\title{
Article \\ The Glyoxylate Cycle Is Involved in White-Opaque Switching in Candida albicans
}

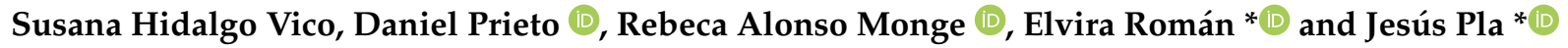 \\ Departamento de Microbiología y Parasitología-IRYCIS, Facultad de Farmacia, Universidad Complutense de \\ Madrid, Avda. Ramón y Cajal s/n, 28040 Madrid, Spain; shvico@ucm.es (S.H.V.); adprieto@ucm.es (D.P.); \\ realonso@ucm.es (R.A.M.) \\ * Correspondence: elvirarg@ucm.es (E.R.); jpla@ucm.es (J.P.)
}

Citation: Vico, S.H.; Prieto, D.; Monge, R.A.; Román, E.; Pla, J. The Glyoxylate Cycle Is Involved in White-Opaque Switching in Candida albicans. J. Fungi 2021, 7, 502. https://doi.org/10.3390/jof7070502

Academic Editor: David S. Perlin

Received: 8 June 2021

Accepted: 22 June 2021

Published: 24 June 2021

Publisher's Note: MDPI stays neutral with regard to jurisdictional claims in published maps and institutional affiliations.

Copyright: (c) 2021 by the authors. Licensee MDPI, Basel, Switzerland. This article is an open access article distributed under the terms and conditions of the Creative Commons Attribution (CC BY) license (https:// creativecommons.org/licenses/by/ $4.0 /)$.

\begin{abstract}
Candida albicans is a commensal yeast that inhabits the gastrointestinal tract of humans. The master regulator of the white-opaque transition WOR1 has been implicated in the adaptation to this commensal status. A proteomic analysis of cells overexpressing this transcription factor $\left(W O R 1^{O E}\right)$ suggested an altered metabolism of carbon sources and a phenotypic analysis confirmed this alteration. The WOR $1^{O E}$ cells are deficient in using trehalose and xylose and are unable to use $2 \mathrm{C}$ sources, which is consistent with a reduction in the amount of Icl1, the isocitrate lyase enzyme. The $i c l 1 \Delta / \Delta$ mutants overexpressing WOR1 are deficient in the production of phloxine B positive cells, a main characteristic of opaque cells, a phenotype also observed in mating type hemizygous $m t l a 1 \Delta i c l 1 \Delta / \Delta$ cells, suggesting the involvement of Icl1 in the adaptation to the commensal state. In fact, $i c l 1 \Delta / \Delta$ cells have reduced fitness in mouse gastrointestinal tract as compared with essentially isogenic heterozygous ICL1/icl1 $\Delta$, but overproduction of WOR1 in an $i c l 1 \Delta / \Delta$ mutant does not restore fitness. These results implicate the glyoxylate shunt in the adaptation to commensalism of $C$. albicans by mechanisms that are partially independent of WOR1.
\end{abstract}

Keywords: commensalism; glyoxylate cycle; wo switching; fungal pathogenesis; epigenetics; opaque cells; oxidative stress

\section{Introduction}

Candida albicans is a commensal yeast that inhabits the gastrointestinal tract of healthy people, where it behaves as a harmless commensal. When host defenses are altered, C. albicans can translocate through the gut epithelium and disseminate via the blood stream, causing severe systemic diseases with as much as 50\% mortality [1-3]. Previously, several virulence factors have been identified in this fungus using an acute systemic infection model in mice [4]. However, in recent years, the popularization of models of colonization of the mammalian gastrointestinal tract [5] has allowed the identification of factors promoting the establishment of the fungus in this location. Inhibition of colonization may promote the eradication (or, at least, the control) of fungal populations in this niche and could be an effective prophylactic approach for the prevention of endogenous candidiasis in immunosuppressed patients [6-9]. Several genes have been shown to be involved in colonization (see [10-12] for recent reviews) and their nature is diverse as they regulate the metabolic status of the fungus and encode components of signaling pathways and/or morphogenetic transitions [13-19].

The white opaque transition (wo) is an environmentally regulated epigenetic program that produces opaque (mating competent) cells from homozygous a/a and $\alpha / \alpha$ diploids, therefore, allowing mating and subsequent tetraploid formation (see [20] for a review). Opaque cells differ from white cells in that they are more elongated, positive to phloxine B staining, and having a distinct transcriptional program [21-23]. The wo conversion has important biological consequences, as opaque cells colonize more readily the skin of mammals [24] but are less virulent as compared with white cells in a mouse model of systemic 
infection [25], consistent with their unstable phenotype at high $\left(37^{\circ} \mathrm{C}\right)$ temperatures. Wor1 is the master regulator of the wo transition; deletion of WOR1 blocks the conversion to the opaque phase and its expression is repressed in heterozygous mating type white cells by the action of two homeodomain proteins $(\mathbf{a} 1 / \alpha 2)$ [26-29]. Other wo regulators have been identified among previously identified opaque-enriched genes $[22,23]$ by in silico selection of transcriptional regulators [30] and the regulatory interactions among them analyzed by chromatin immunoprecipitation and gene expression profiling $[30,31]$ or by a systematic screening using a collection of strains deleted for transcription factors [32]. The complexity of this transition is revealed by the involvement of chromatin reorganization via histone modifications [33-35].

Interestingly, Wor1 is involved in the wo transition and also in the adaptation to commensalism. This was suggested by the fact that the morphogenetic regulator Efg1 [36], also involved in the wo transition [37], is an important regulator of fungal loads in mouse gastrointestinal (GI) tract, as efg $1 \Delta$ cells show higher fungal levels in the gut as compared with wild type cells [15]. WOR1 overexpression (WOR $1^{O E}$ ) from the MET3 promoter provokes an en masse conversion of the white population to phloxine B positive cells in a / $\alpha$ mating type cells [29], thus, overriding repression by the a1 $\alpha 2$ dimer. WOR $1^{O E}$ a $/ \alpha$ cells have an increased fitness in mouse GI tract [27], in striking contrast with the behavior of opaque cells derived from spontaneous switching of mating type homozygous cells that are rapidly lost [27]. Therefore, Wor1 has been suggested to mediate a morphological switch (termed GUT from gastrointestinally induced transition) via its increased expression upon passage through the mouse intestine, presumably converting a subset of $C$. albicans cells to the commensal status. GUT cells are morphologically slightly different from opaque cells and display a specific transcriptional program [27].

The changes occurring in WOR $1^{O E}$ cells that lead to an increase in fitness are not completely understood. Pande et al. reported significant changes in lipid, glucose, and iron metabolism genes and an increased expression of genes involved in $\mathrm{N}$-acetyl glucosamine metabolism, a monosaccharide produced primarily by GI tract bacteria [27]. WOR1 ${ }^{O E}$ cells have an altered consumption of glucose and are sensitive to antimycin A [38], suggesting an altered balance in their respiratory metabolism. In this study, we characterized the phenotype of WOR $1^{O E}$ cells by different means. A proteomic analysis of WOR1 overexpressing cells reveals changes in enzymes involved in the utilization of certain carbon sources and a repression of the glyoxylate cycle in these cells. We demonstrate that the growth of WOR $1^{O E}$ cells is altered in the presence of alternative carbon sources and show a role for the glyoxylate cycle in the production of opaque cells and the fitness of $C$. albicans cells in mouse GI tract.

\section{Materials and Methods}

\subsection{Strains and Growth Conditions}

All C. albicans strains used in this work are listed in Table 1. The construction of strains defective in ICL1 or MTLa1 or those overproducing Wor1 are described in the next section. In addition to the standard collection name, we provide a more descriptive name used in this manuscript.

Yeast strains were routinely grown at $37{ }^{\circ} \mathrm{C}$ in YPD liquid medium ( $2 \%$ glucose, $2 \%$ peptone, and $1 \%$ yeast extract). Growth was estimated by $\mathrm{OD}_{600}$ measurements. Drop tests for susceptibility/resistance or growth on carbon sources assays were performed by spotting $5 \mu \mathrm{L}$ drops containing $10^{5}$ cells and ten-fold serial dilutions of stationary cells (grown for $18-20 \mathrm{~h}$ in YPD liquid medium at $37^{\circ} \mathrm{C}$ ) onto minimal medium (MM) agar plates $(0.5 \%$ ammonium sulphate, $0.17 \%$ yeast nitrogen base without amino acids, and $2 \%$ agar) which was supplemented with $0.2 \%$ of sodium acetate, sodium citrate, ethanol, glycerol, glucose or $0.1 \%$ of olive oil $/ 0.2 \%$ Tween 80 . Plates were incubated at $37{ }^{\circ} \mathrm{C}$ for $72 \mathrm{~h}$. Growth on xylose or trehalose was performed in 96-well microtiter plates by inoculating $10^{3}$ cells per well in MM supplemented with the indicated concentrations of xylose or trehalose and incubated at $37^{\circ} \mathrm{C}$ for 2 or 6 days, respectively. Observation of 
white/opaque colonies was performed by spreading 200 colony forming units (CFUs) on YPD supplemented with $10 \mu \mathrm{g} / \mathrm{mL}$ of phloxine B (Sigma-Aldrich, city, state, country) and incubated for $48 \mathrm{~h}$ before photographs were taken. To induce white-opaque switching, 300 CFUs were spread per YPD plate $(\mathrm{pH}=6)$ and supplemented with $5 \mu \mathrm{g} / \mathrm{mL}$ of phloxine B [43]. Plates were incubated at $28^{\circ} \mathrm{C}$ for $48-72 \mathrm{~h}$ covered in aluminum foil. Fresh stools from mice collected during in vivo fitness assays were homogenized in sterile water and plated on SD medium ( $2 \%$ glucose, $0.5 \%$ ammonium sulphate, $0.17 \%$ yeast nitrogen base, amino acids, and $2 \%$ agar) supplemented with $20 \mu \mathrm{g} / \mathrm{mL}$ chloramphenicol.

Table 1. Strains of C. albicans used in this study.

\begin{tabular}{|c|c|c|c|}
\hline Strain Name & Common Name in Manuscript & Background Strain and Genotype & Source \\
\hline CAI4 & & 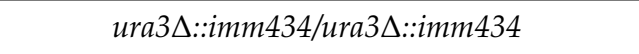 & [39] \\
\hline CAI4-pNRUe & & [CAI4] ADH1/adh1::tTATET $T^{P R_{-m y c-U R A 3}}$ & [40] \\
\hline CAI4-RFP & & $\begin{array}{c}\text { [CAI4] ADH1/adh1:: } \\
\text { tTATET }^{P R_{-}} \text {dTOM2-URA3 }\end{array}$ & {$[38]$} \\
\hline CAI4-WOR $1^{\mathrm{OE}}$ & & $\begin{array}{c}\text { [CAI4] ADH1/adh1:: } \\
\text { tTATET }{ }^{P R}-W O R 1-m y c-U R A 3\end{array}$ & [38] \\
\hline MLC9 & & [CAI4] icl1::hisG/icl1::hisG & [41] \\
\hline MRC10 & $i c l 1 \Delta / \Delta$ & [CAI4] icl1::hisG/icl1::hisG RPS10/rps10::URA3 & [42] \\
\hline MRC11 & $i c l 1 \Delta / \Delta$-pICL1 & {$[i c l 1 \Delta / \Delta]$ RPS10/rps10::ICL1-URA3 } & [42] \\
\hline SHV1 & $i c l 1 \Delta / \Delta$-pICL1-GFP & $\begin{array}{c}{[i c l 1 \Delta / \Delta \text {-pICL1] ADH1/adh1:: }} \\
\text { tTATET }^{P R} \text {-GFP-myc-SAT1 }\end{array}$ & This study \\
\hline SHV2 & $i c l 1 \Delta / \Delta-\mathrm{RFP}$ & $\begin{array}{c}{[i c l 1 \Delta / \Delta] \text { ADH1/adh1:: }} \\
t_{T A T E T^{P R}}-d T O M 2-S A T 1\end{array}$ & This study \\
\hline SHV3 & $i c l 1 \Delta / \Delta$-pNRUe & {$[i c l 1 \Delta / \Delta]$ ADH1/adh1::tTATET ${ }^{P R_{-m y c-U R A 3}}$} & This study \\
\hline SHV4 & $i c l 1 \Delta / \Delta-W O R 1^{O E}$ & $\begin{array}{c}{[i c l 1 \Delta / \Delta] \text { ADH1/adh1:: }} \\
\text { tTATET }{ }^{P R}-W O R 1-m y c-U R A 3\end{array}$ & This study \\
\hline SHV5 & $i c l 1 \Delta / \Delta-m t l a 1 \Delta$ & {$[i c l 1 \Delta / \Delta] m t l a 1 \Delta:: S A T 1$} & This study \\
\hline SHV6 & $i c l 1 \Delta / \Delta$-pICL1-mtla1 $\Delta$ & {$[i c l 1 \Delta / \Delta$-pICL1] mtla1 $\Delta:: S A T 1$} & This study \\
\hline
\end{tabular}

\subsection{Genetic Procedures}

The pNIM1R-dTOM2 and pNIM1R-GFP [17] plasmids were both used to generate fluorescent $i c l 1 \Delta / \Delta$-RFP and icl1 $\Delta / \Delta$-pICL1-GFP labeled strains. These plasmids allow a repressible tetracycline dependent regulation of both fluorescent proteins (TET-OFF system) and carry the $S A T 1$ dominant marker. The products after digestion with $K p n \mathrm{I}$ and $K s p \mathrm{I}$ restriction enzymes were integrated at the $A D H 1$ locus of $i c l 1 \Delta / \Delta$ and $i c l 1 \Delta / \Delta$-pICL1 $C$. albicans strains. Transformants were selected on YPD supplemented with $200 \mu \mathrm{g} / \mathrm{mL}$ of nourseothricin. Empty control vector pNRUe [40] and pNRUX-WOR1-myc [38] tetracycline repressible plasmids that carry the URA3 marker were digested with KpnI and KspI and products were integrated at the $A D H 1$ region of the MLC9 strain to generate $i c l 1 \Delta / \Delta$ pNRUe and icl1 $\Delta / \Delta-\mathrm{WOR} 1^{\mathrm{OE}}$ strains. Transformants were selected in SD plates with $2 \%$ glucose and without uracil. C. albicans transformation by electroporation was performed using described procedures [40].

Deletion of MTLA1 gene was performed using the Transient CRISPR-Cas9 system [44,45]. The CaCAS9 cassette was amplified from the plasmid pV1093 [46]. The sgRNA cassette expressed under the SNR52 promoter and directed against the MTLA1 region was constructed by single-joint PCR. A first round PCR was carried out by amplification of the SNR52 promoter and the 20 bp overlapping MTL1 guide sequence by using SNR52/F forward primer and SNR52/R_MTL1 reverse primer. The second round PCR amplified the $20 \mathrm{bp}$ complementary guide sequence and the sgRNA scaffold by using the sgRNA/F_MTL1 forward primer sgRNA/R reverse primer. First and second round PCRs were carried out by using the 
pV1093 plasmid as a template. Third round nested PCR for construction of the sgRNA expression cassette used both PCR products and SNR52/N forward primer and sgRNA/N reverse primer. The repair template cassette which contains the SAT1 selection marker and 80 bp MTLA1 additions on both sides was amplified from pNIM1R-RFP by using MATa1_del_F forward primer and MATa1_del_R reverse primer. The guide sequence from the sgRNA cassette hybridizes at the MTLA1 region enabling CaCas9 to break the double strand, triggering the homology-directed repair by integration of the $S A T 1$ cassette. PCR products of CaCAS9, sgRNA, and SAT1 repair template cassettes were used to co-transform icl1 $\Delta / \Delta$ and icl1 $\Delta / \Delta$-pICL1 strains following the same procedure and selected on YPD supplemented with nourseothricin; icl1 $\Delta / \Delta$-pICL1 is a reintegrant strain in the RPS10 locus where ICL1 expression is driven from its own promoter. Genomic DNA from transformants was used to determine MTLA1 deletion by PCR using oRS108 forward primer (inside MTLA1 sequence), Comp_del_F forward primer (inside SAT1 sequence), and oRS109 reverse primer (outside of recombination site). All primers are listed in Table 2.

Table 2. Primers used in this study.

\begin{tabular}{|c|c|}
\hline Primer Name & Sequence $\left(5^{\prime} \rightarrow 3^{\prime}\right)$ \\
\hline SNR52/F & AAGAAAGAAAGAAAACCAGGAGTGAA \\
\hline SNR52/R_MTL1 & CTCACGCTTCAATTGTAAGACAAATTAAAAATAGTTTACGCAAGTC \\
\hline sgRNA/F_MTL1 & TCTTACAATTGAAGCGTGAGGTTTTAGAGCTAGAAATAGCAAGTTAAA \\
\hline $\operatorname{sgRNA} / \mathrm{R}$ & ACAAATATTTAAACTCGGGACCTGG \\
\hline SNR52/N & GCGGCCGCAAGTGATTAGACT \\
\hline sgRNA/N & GCAGCTCAGTGATTAAGAGTAAAGATGG \\
\hline MATa1_del_F & $\begin{array}{c}\text { TTTCTGCGTATTGTGATAAATAACTTTTTTTCCCTCTAAAAATATTGATTAGAGGCAC } \\
\text { AAAATAAAAATCACCTTCAACCCGTCAAAACTAGAGAATAATAAAGAAAACG }\end{array}$ \\
\hline MATa1_del_R & $\begin{array}{l}\text { CCCACCAAGACATGTTACGAATAGATCTATTAGTTAGCAATATTCTGTTTGATAAT } \\
\text { ACATACCCAAACTCTTATTTGGGAGCAGGACCACCTTTGATTGTAAATAG }\end{array}$ \\
\hline Comp_del_F & CACGTATAAAACTAGACCTCAAGTCTCG \\
\hline oRS108 & ATGAACTCAGAAATAGAAAGTAGC \\
\hline oRS109 & CTAGGTTGAATTTGAACTTGATTT \\
\hline
\end{tabular}

\subsection{Protein Extraction and Proteomics Analysis}

Proteins were extracted from $300 \mu \mathrm{L}$ overnight cultures (18-20 h of growth in YPD medium at $37^{\circ} \mathrm{C}$ ). These conditions were chosen for proteomic analysis as they gave a superior reproducibility in test pilot studies. Under these conditions, most of the cells remained in yeast form. Cell extracts were obtained by using glass beads in a Fast prep breaker, as described previously [47]. The supernatant was collected, and the protein concentration was measured using a Bradford assay. Protein extracts were precipitated with $\mathrm{MeOH} /$ chloroform and resuspended in $8 \mathrm{M}$ Urea. Protein extracts $(100 \mu \mathrm{g})$ were reduced with $10 \mathrm{mM}$ DTT (Sigma-Aldrich) for $1 \mathrm{~h}$ at $37^{\circ} \mathrm{C}$ followed by alkylation with $55 \mathrm{mM}$ iodoacetamide (Sigma-Aldrich) for $1 \mathrm{~h}$ in the dark at room temperature. Proteins were digested with 1/50 (w/w) of recombinant trypsin (Roche Molecular Biochemicals, Mannheim, Germany) in $25 \mathrm{mM}$ ammonium bicarbonate adjusted to $\mathrm{pH}=8.5$ and incubated overnight at $37^{\circ} \mathrm{C}$. Digested peptides were desalted and concentrated, as described before [48]. Peptides were analyzed by reverse phase liquid chromatography electrospray ionization tandem mass spectrometry (RP-LC-ESI-MS/MS) on a nano Easy-nLC 1000 (ThermoScientific, San Jose, CA, USA,) coupled to a Q-Exactive HF mass spectrometer (Thermo Scientific). Desalted peptides were concentrated by loading them on an Acclaim PepMap 100 column (Thermo Scientific, $20 \mathrm{~mm} \times 75 \mu \mathrm{m}$ inner diameter, $3 \mu \mathrm{m}$ diameter $\mathrm{C} 18$ and $100 \AA$ A pore size). Peptides were separated and eluted on a C18 Picofrit column (Thermo Scientific Easy Spray Column, PepMap RSLC C18 $500 \mathrm{~mm} \times 75 \mu \mathrm{M}$ inner diameter, $2 \mu \mathrm{M}$ 
diameter, $100 \AA$ pore size) with an integrated spray tip at a flow rate of $250 \mathrm{~nL} / \mathrm{min}$ for $240 \mathrm{~min}$. Buffer A ( $2 \%$ acetonitrile and $0.1 \%$ formic acid) and buffer B $(0.1 \%$ formic acid on acetonitrile, gradient from 2 to $40 \%$ ) were used. Peptides were detected with a Q-Exactive mass spectrometer at a $\mathrm{m} / \mathrm{z}$ range of 350-2000 Da with a mass resolution of 60,000 and acquired using data-dependent acquisition (DDA). The 15 most abundant precursors with charges of $2-6+\left(\right.$ threshold $8 \times 10^{3}$ ) were selected for higher energy collisional dissociation (HCD) fragmentation with a dynamic exclusion of $27 \mathrm{~s}$. The normalized collision energy was $27 \%$.

Peptide identification was carried out by using the Mascot v. 2.6 .1 search engine (MatrixScience) through the Protein Discoverer 2.2 Software (Thermo Scientific) and the CGD21 database from http:/ / www.candidagenome.org accessed on date 10 April 2018. The following parameters were used: tolerances of $10 \mathrm{ppm}$ for precursor ions and $0.02 \mathrm{Da}$ for MS/MS fragment ions, up to two missed cleavage sites from trypsin digestion and allowing optional methionine oxidation and fixed carbamidomethylation of cysteine. The acceptance criteria for protein identification were an FDR $<1 \%$ and at least one unique peptide identified with high confidence (percolator $q$-value $<0.01$ ). Protein quantification was carried out, as previously described [48]. Protein extracts were treated for mass spectrometry at the Proteomics Unit of the Universidad Complutense de Madrid.

CGD was the main database used for the functional classification. GO Slim Mapper tool was used for the analysis by cellular component, while the ontological enrichment analysis by biological process was carried out by PathoYeastract, Rank by GO.

\subsection{In Vivo Procedures}

In vivo fitness assays were performed on 7-10-week-old female mice C57BL/6 (Charles River Laboratories España S.A.U, St. Cugat del Vallés, Barcelona, España) [17]. In these experiments, two different genetically labeled strains (either GFP or RFP) were administered by gavage and the relative colonization of each strain was determined by counting green/red colonies, as described by [17]. Genetic labeling was stable and resulted in a rather homogenous fluorescence in all cells leading to easily distinguishable colonies on solid medium. Colonization assays were started four days before with antibiotic pretreatment $(2 \mathrm{mg} / \mathrm{mL}$ streptomycin, $1 \mathrm{mg} / \mathrm{mL}$ bacitracin, and $0.1 \mathrm{mg} / \mathrm{mL}$ gentamycin) and $0.25 \mathrm{mg} / \mathrm{mL}$ fluconazole added to drinking water. One day before inoculation, fluconazole was retired and a single gavage of $10^{7}$ cells in $100 \mu \mathrm{L}$ PBS was then intragastrically inoculated. Fresh stool samples were collected from each mouse every 2-4 days and mechanically homogenized in PBS. Ten-fold serial dilutions were plated on SD medium supplemented with $20 \mu \mathrm{g} / \mathrm{mL}$ chloramphenicol and incubated at $37^{\circ} \mathrm{C}$ for 2 days. The fungal population was quantified by CFU determination. Experiments involving animals were carried out in the animal facility at the Medical School of the Universidad Complutense de Madrid in strict accordance with the regulations "Real Decreto 1201/2005, BOE 252" for the Care and Use of Laboratory Animals of the "Ministerio de la Presidencia," Spain. The commensalism model used in these experiments was approved by the Animal Experimentation Committee of the University Complutense of Madrid (CEA 33-2015) and Comunidad de Madrid according to Artículo 34 del RD 53/2013 (PROEX 226/15). The treatments did not result in disease and procedures minimized any suffering. The number of animals used in every experiment was adjusted to a minimum for ethical reasons.

\section{Results}

\subsection{Analysis of Proteome in WOR1 Overexpressing Cells}

To characterize the phenotype of WOR $1^{\mathrm{OE}}$ cells, we used strain CAI4-WOR1 ${ }^{\mathrm{OE}}$ [38], a CAI4-derived strain (being therefore mating type a/ $\alpha$ cells) where the expression of an ectopically integrated wild type allele of WOR1 is under the strong and tightly regulated $\mathrm{TET}^{\mathrm{OFF}}$ promoter, a tetracycline repressible version of the TET promoter [49]. We performed a proteomic analysis of these cells after growing for $18-20 \mathrm{~h}$ in YPD medium at $37^{\circ} \mathrm{C}$ as compared with the same strain carrying the empty vector (CAI4-pNRUe). Whole cell ex- 
tracts were obtained from these cells and subjected to LC-MS/MS (liquid chromatography mass spectrometry analysis, Thermo Scientific, San Jose, CA, USA). Among the 3254 identified proteins, only 3190 could be quantified. To determine the number of proteins that decreased or increased in the CAI4-WOR $1{ }^{\mathrm{OE}}$ strain, we used the $\log _{2}$ ratio $<-0.5$ or $\log _{2}$ ratio $>0.5$, respectively, and only considered peaks with a CAI4-WOR $1^{\mathrm{OE}} / \mathrm{CAI} 4-\mathrm{pNRUe}$ (control strain) abundance ratio with a statistical significance $p<0.05$ (expressed as $-\log 10$ $p>1.3$ ). This resulted in 242 proteins that are represented in the Volcano plot (Figure 1A). We also considered proteins that showed a variability ratio $<30 \%$ between replicates, had more than one identified peptide, and a Mascot score $>13$ resulting in 379 proteins; 37 were only detected in the CAI4-pNRUe control strain (abundance ratio expressed in $\log 2<-6.64), 169$ were only detected in the $\mathrm{WOR} 1^{\mathrm{OE}}$ strain $(\log 2>6.64)$, and 173 were common to both. Within this subset, 163 proteins were less abundant in the CAI4-WOR $1{ }^{\mathrm{OE}}$ strain, while only a few (10) were increased (Figure 1B).

A

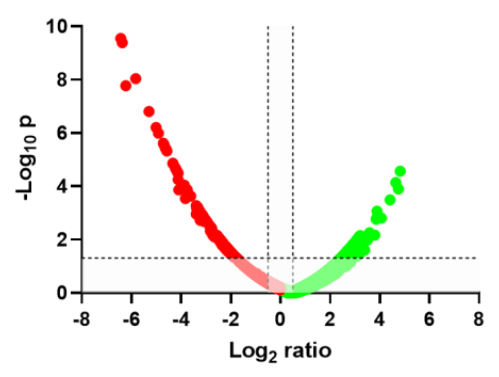

B

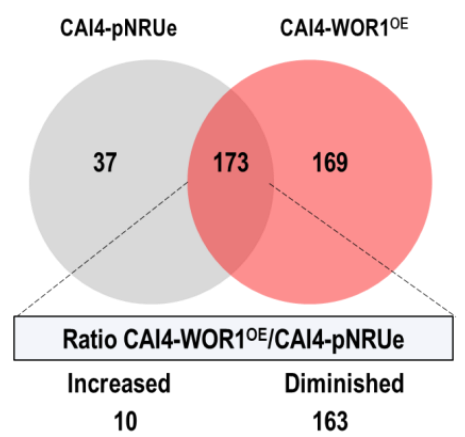

Figure 1. Proteome changes in cells overproducing Wor1. (A) Volcano plot of differentially abundant proteins (CAI4-WOR1 ${ }^{O E} /$ CAI4-pNRUe ratio). The $\log _{10}$ of the $p$-value is plotted against abundance $\left(\log _{2}\right.$ ratio) for each individual protein. Proteins that were found in lower abundance in WOR1 ${ }^{O E}$ cells are shown in red whereas proteins with higher abundance are shown in green. Horizontal dotted line indicates the limit for $p$-values $\left(p=0.05\right.$, that correspond to $-\log _{10} \mathrm{p}=1.3$ ). Vertical dotted lines indicate the $\log _{2}$ ratio $= \pm 0.5$ threshold. (B) Venn diagram with the number of proteins identified exclusively in one strain or in both strains, based on a variability ratio $<30 \%$ between replicates and a Mascot score $>13$.

Among those proteins less abundant in WOR1 ${ }^{O E}$, we identified cytoplasmic (74), nuclear (32), mitochondrial (25) or ribosomal proteins (24), as well as proteins located in the mitochondrial envelope (15), plasma membrane (14), cell wall (13), cytoskeleton (7), vacuole (3), peroxisome (2), endoplasmic reticulum (2), or Golgi (2). Among the 10 proteins identified with highest abundance in the CAI4-WOR $1^{\mathrm{OE}}$ strain, we identified proteins located in the nucleus (5), cytoplasm (3), and mitochondria (2). Wh11, a protein only found in white budding-phase cells and absent in opaque budding phase cells, or Adh5, regulated by white-opaque switch, were less abundant in cells overproducing Wor1, thus, validating our data.

Our analysis revealed a significant decrease in the abundance of proteins involved in carbon metabolism and nutrient acquisition processes, such as Icl1 (isocitrate lyase), Pck1 (phosphoenolpyruvate kinase), Adh5 (alcohol dehydrogenase), Glx3 (glutathioneindependent glyoxalase), and the high affinity transporters for glucose Hgt1 and Hgt19. We also found proteins within this subset related to mitochondria at different steps such as the import and sorting of proteins of nuclear origin. We also found within this subset the translocase of the outer membrane (TOM) complex that mediates translocation of proteins across or into the outer membrane (OM). In particular, Tom22 or the orf19.6062; orf19.6062, the putative Tim 23 translocase subunit which takes in proteins with a cleavable mitochondrial targeting sequence (MTS) directing them into the matrix or the inner membrane. We also found Tim9, Tim13, and Tim22 together with small soluble proteins in the IMS (called 
Tim), which deliver into the IM the proteins of the so-called mitochondrial carrier family (MCF) that lacks a cleavable MTS. Others were enzymatic systems involved in mitochondrial oxidative phosphorylation (OXPHOS), such as the cytochrome-c oxidase Cox4, or Cyb5 (cytochrome b5) that form part of the electron chain, or C1_06840cp_a, C2_01720cp_a, and C7_01610wp_that are involved in the assembly of complex IV cytochrome-b oxidase, or Atp20 (subunit $g$ of the mitochondrial membrane ATP synthase). We also found some proteins that form part of mitochondrial ribosomes such as C1_0670wp_a y Cr_04580wp_a. A set of proteins related to the cellular response to stress were also decreased, such as the oxido reductases Pst2 and Cip1, the catalase Cat1, and the thioredoxin peroxidase Dot5.

A total of 169 proteins were only found in the $W O R 1^{O E}$ strain. The analysis by cellular component determined that most of the proteins were located in the nucleus (60) followed by the cytoplasm (57), membrane (37), chromosome (22), nucleolus (13) plasma membrane (12), Golgi apparatus (9), mitochondria (8), endoplasmic reticulum (8), cytoskeleton (8), vacuole (5), and peroxisome (3), among others (Supplementary List).

\subsection{WOR1 Is Involved in the Use of Non-Fermentable Two Carbon Sources}

As proteomics revealed changes in the enzymes involved in carbon metabolism, we tried to determine the behavior of cells in specific carbon sources. We determined the ability to grow on minimal media at $37^{\circ} \mathrm{C}$ using trehalose and xylose as carbon sources (Figure 2A,B) by measuring O.D. The O.D. reached under the conditions tested ( 2 days for xylose and 6 days for trehalose) by CAI4-WOR1 ${ }^{\mathrm{OE}}$ strain grown in xylose containing medium was $30-40 \%$ of the parental strain; these defects were more evident in the presence of trehalose, as WOR $1^{O E}$ cells were completely unable to use this disaccharide as a carbon source (Figure 2B).

A
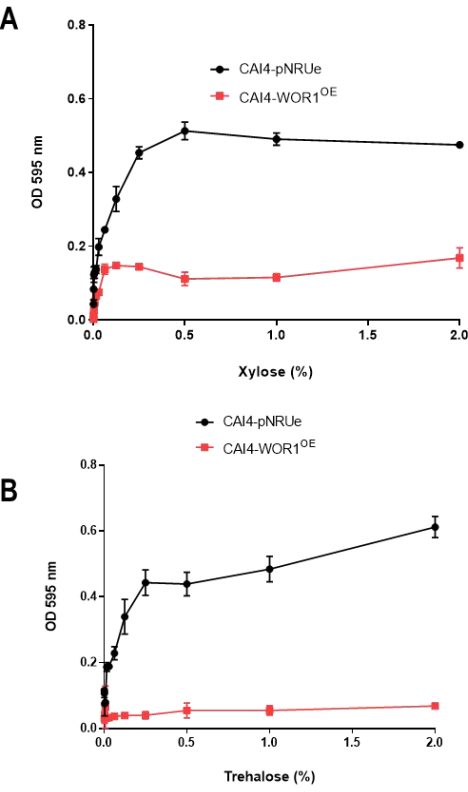

C

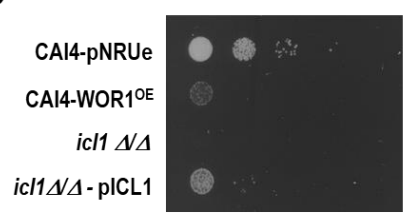

EtOH $0.2 \%$

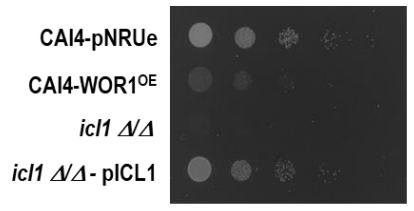

GLU $0.2 \%$

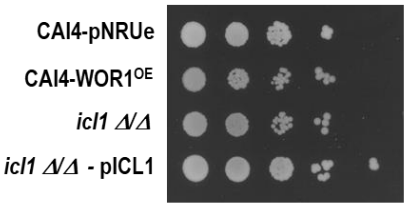

CIT $0.2 \%$

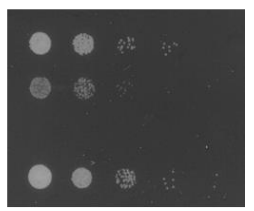

GLY $0.2 \%$

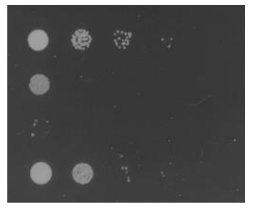

Olive oil $0.1 \%$

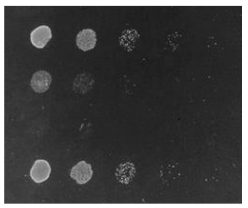

Figure 2. Comparative growth of strains in different carbon sources. Growth of pNRUe and WOR1 ${ }^{O E}$ strains on MM medium supplemented with different concentrations of (A) xylose or (B) trehalose. The 96-well microtiter plates were incubated for 2 days (xylose) or 6 days (trehalose). Values are mean \pm standard deviation of three independent replicates. (C) $10^{5}$ cells and ten-fold dilutions from overnight growing cells from CAI4-pNRUe, CAI4-WOR1 $O E$, icl1 $\Delta / \Delta$, and icl1 $\mathbf{\Delta} / \mathbf{\Delta}$ pICL1 strains were spotted onto MM plates without amino acids and supplemented with $0.2 \%$ of sodium acetate (Ace), sodium citrate (CIT), ethanol (EtOH), glycerol (GLY), glucose (GLU), or olive oil. Plates were incubated at $37^{\circ} \mathrm{C}$ for $72 \mathrm{~h}$ before being scanned.

Interestingly, our proteome analysis also revealed that the isocitrate lyase Icl1, a key enzyme in the glyoxylate cycle, showed reduced levels when WOR1 was overexpressed (the $\log 2$ ratio $W O R 1^{O E} / \mathrm{pNRUe}$ was -3.76 ). The glyoxylate cycle allows cells to use two carbon 
sources bypassing two sequential decarboxylation steps in the Krebs cycle [41]. Therefore, we analyzed the growth of WOR $1^{O E}$ cells on different carbon sources in solid media. The overexpression of WOR1 resulted in a significant growth defect in nonfermentable carbon sources such as acetate, citrate, ethanol, and glycerol in a standard drop assay (Figure 2C), a phenotype resembling those of $i c l 1 \Delta / \Delta$ mutants [41] (Figure 2C). Such differences were not observed in the presence of the fermentable carbon source glucose. Growth defects were also observed in olive oil supplemented minimal medium, consistent with the role of the glyoxylate cycle in metabolizing acetyl-CoA intermediates derived from the $\beta$-oxidation of fatty acids. We conclude that overexpression of WOR 1 in C. albicans alters the carbon metabolism of the cells by reducing its ability to use some carbohydrates and, mainly, two carbon sources probably via a reduction in the glyoxylate shunt.

\section{3. icl1 $\Delta / \Delta$ mutants Fail to Produce Phloxine B+ Cells in WOR1 Overexpressing Cells}

Given the defects in the utilization of carbon sources by WOR1 overexpressing cells, we analyzed the role of the glyoxylate cycle in $W O R 1^{O E}$. For this purpose, we ectopically expressed WOR1 from the constitutive TET ${ }^{\mathrm{OFF}}$ promoter in icl1 $\Delta / \Delta$ mutants and noticed that the production of phloxine B positive cells in icl1 $\triangle / \triangle-W O R 1^{O E}$ cells was defective at $37^{\circ} \mathrm{C}$, with most of the cells being mainly negative (or very slightly pink), indicating a defect in retaining this fluorochrome (Figure $3 \mathrm{~A}$ ). This effect was observed both at $37^{\circ} \mathrm{C}$ and $30^{\circ} \mathrm{C}$ (not shown) and was largely suppressed by high temperature $\left(42{ }^{\circ} \mathrm{C}\right)$. Cells from the $i c l 1 \Delta / \Delta-W O R 1^{O E}$ mutant at $37^{\circ} \mathrm{C}$ showed a heterogeneous colony size, with a reduced number of small colonies that retained more actively the fluorochrome with cells resembling those found in WOR $1^{O E}$ strains (with larger cells with a larger vacuole, but not true elongated as opaque cells). However, the most abundant bigger colonies were white and phloxine B negative with typical rounded cells (Figure 3B); however, this did not occur with wild type WOR $1^{O E}$ cells being all of them phloxine $\mathrm{B}+$.

These results, obtained from an artificial and ectopically expressed WOR1, prompted us to investigate whether the glyoxylate cycle could be involved in opaque cell formation. As this spontaneous conversion occurs in a $\alpha$ hemizygous mating-type cells, we deleted the mating gene MTLa1 in $i c l 1 \Delta / \Delta$ mutants and $i c l 1 \Delta / \Delta /$ ICL1 reintegrants (see Material and Methods) and analyzed the production of opaque cells at $28{ }^{\circ} \mathrm{C}$ in $5 \% \mathrm{CO}_{2}$ atmosphere. As shown in Figure 4 , icl1 $\Delta / \Delta$-mtla1 mutants switched $4.4+/-2.1$ times less frequently than $i c l 1 \Delta / \Delta / I C L 1-m t l a 1$ heterozygous cells. No statistical differences were found with light pink colonies. In addition, opaque cells appeared as smaller colonies as compared with white cells, suggesting the importance of a functional glyoxylate cycle in opaque cells. Collectively, these results indicate that the conversion to the opaque phase is influenced by a functional glyoxylate cycle and suggests that $W O R 1^{O E}$ regulates this conversion, at least in part, via repression of this pathway.

\section{4. icl1 $\Delta / \Delta$ Mutants Are Defective in Gastrointestical Colonization}

As WOR $1^{O E}$ has been shown to influence gastrointestinal colonization improving the fitness of C. albicans (deletion of WOR1 reduces fitness) [27], we wondered whether deletion of ICL1 would also affect colonization. For this purpose, we used a competitive fitness assay between $i c l 1 \Delta / \Delta$ and $i c l 1 \Delta / \Delta$-pICL1 mutants. Cells were genetically labeled with GFP or RFP and inoculated as a 1:1 inoculum of both cell types by gavage to mice. As shown in Figure $5 \mathrm{~A}$, the $i c l 1 \Delta / \Delta$ mutant showed fitness defects as compared with isogenic icl1 $\Delta / \Delta$ pICL1 cells, with a continuous and slow reduction in fungal colonization (determined by CFUs in stools). The icl1 $\Delta / \Delta$ cells were outcompeted by the reintegrated ICL1 strain, being evident from day 15 onwards until they were not detected in most mice after $\approx 30$ days of growth. To determine whether $i c l 1 \Delta / \Delta$ colonization defects could be restored by WOR1 ${ }^{O E}$, we did a similar experiment with icl1 $\Delta / \Delta$ and $i c l 1 \Delta / \Delta-W O R 1^{O E}$ cells. As shown in Figure $5 \mathrm{~B}$, the overproduction of WOR1 does not outcompete an $i c l 1 \Delta / \Delta$ mutant. 
A

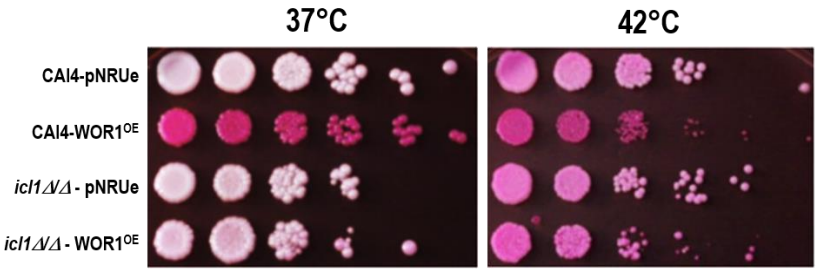

B
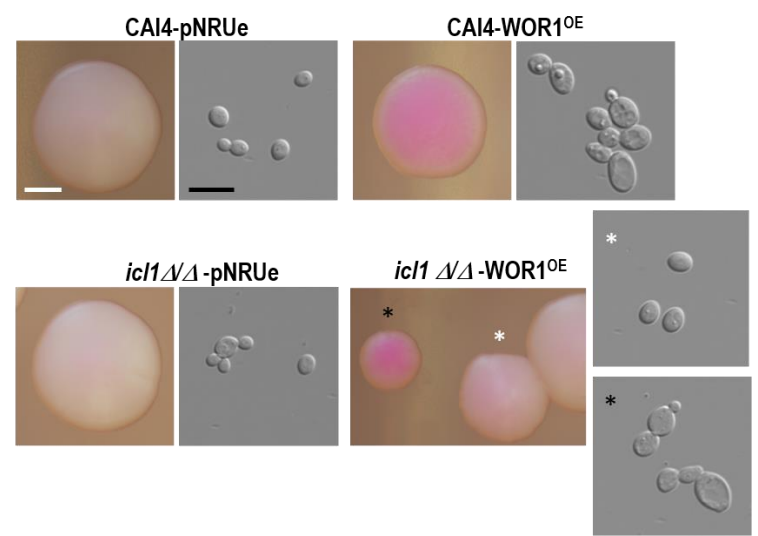

Figure 3. Effect of WOR1 overexpression on phloxine B+ cell formation in wt and icl1 $\Delta / \Delta$ backgrounds. (A) Production of phloxine B + cells. Cells were grown for $18-20 \mathrm{~h}$ at $37^{\circ} \mathrm{C}$. Cells of CAI4-pNRUe, CAI4-WOR $1^{\mathrm{OE}}$, $i c l 1 \Delta / \Delta$, and $i c l 1 \Delta / \Delta-\mathrm{WOR} 1^{\mathrm{OE}}$ strains were spotted onto YPD supplemented with $10 \mu \mathrm{g} / \mathrm{mL}$ of phloxine B and incubated at $37^{\circ} \mathrm{C}$ for $48 \mathrm{~h}$. (B) $200 \mathrm{CFUs}$ were spread on the same media and incubated at $37^{\circ} \mathrm{C}$ for $48 \mathrm{~h}$. White scale bar stands for $0.5 \mathrm{~mm}$; black scale bar stands for $10 \mu \mathrm{m}$. Photographs of individual colonies and their corresponding cells are shown and marked with either a white or black asterisk.

A
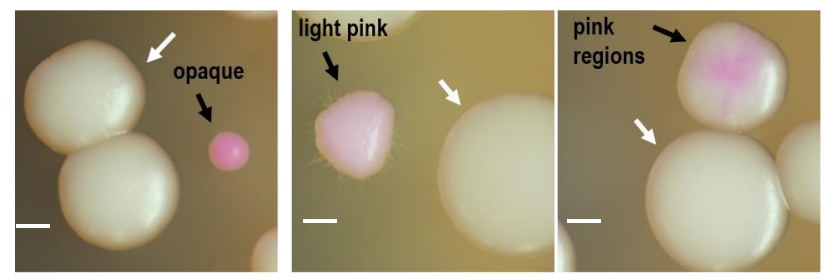

B

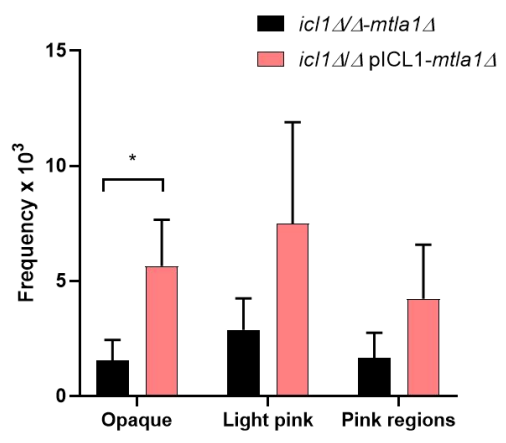

Figure 4. Induction of white-opaque conversion in $i c l 1 \Delta / \Delta-m$ tla1 and $i c l 1 \Delta / \Delta /$ ICL1-mtla1 strains. $300 \mathrm{CFUs}$ were spread onto $\mathrm{YPD} \mathrm{pH}=6$ plates supplemented with $5 \mu \mathrm{g} / \mathrm{mL}$ phloxine $\mathrm{B}$ and incubated in the dark for 2 days at $28{ }^{\circ} \mathrm{C}$ and $5 \% \mathrm{CO}_{2}$. The upper picture (A) indicates the appearance of the different counted colonies as standard white colonies (white arrows) or pink colored colonies (black arrows), either opaque, light pink, or mixed colored colonies (pink regions) in $i c l 1 \Delta / \Delta-m t l a 1$. White scale bar stands for $1 \mathrm{~mm}$. Data (B) are shown as mean with standard deviation (SD) from six independent experiments ( $n \approx 2500$ colonies from each strain per experiment). The frequency (colonies of the indicated type/1000 total colonies) is represented. A $t$-test was used to determine the significance $\left(p=0.021,{ }^{*} p<0.05\right)$. 
A

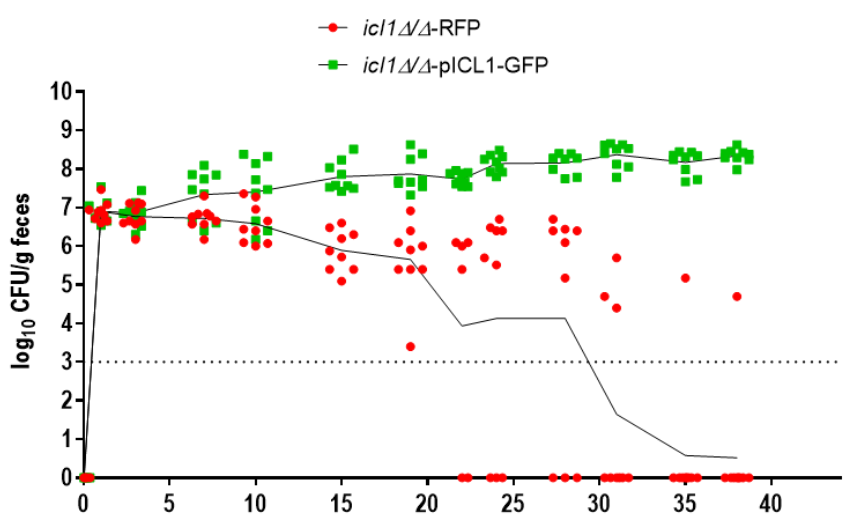

B

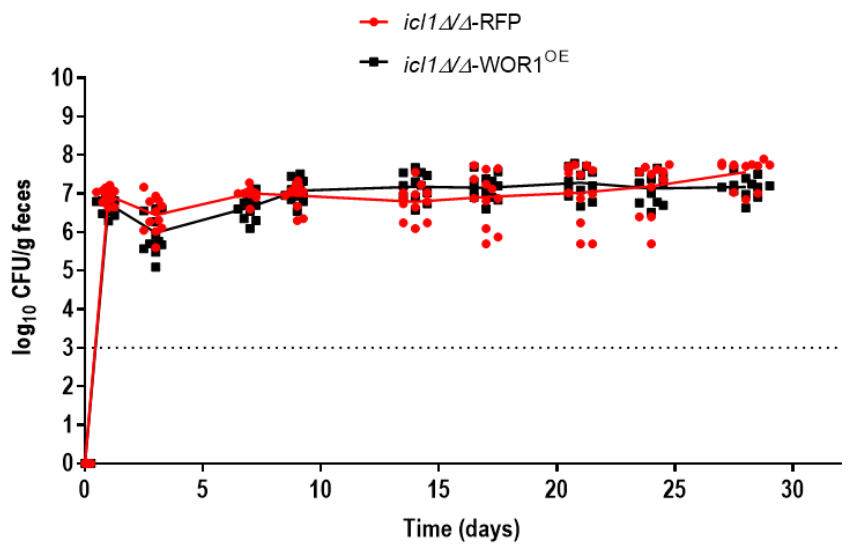

Figure 5. Gastrointestinal colonization of $i c l 1 \Delta / \Delta$ mutants. Oral antibiotic therapy was given to mice starting 4 days before inoculation by gavage of $10^{7}$ cells of a $1: 1$ mixture of $i c l 1 \Delta / \Delta-R F P$ and $i c l 1 \Delta / \Delta$-pICL1-GFP $(n=9)(\mathbf{A})$ or $i c l 1 \Delta / \Delta$-RFP and $i c l 1 \Delta / \Delta-W O R 1^{\mathrm{OE}}(n=12)(\mathbf{B})$. The dotted line indicates the limit of detection of the method used.

These results demonstrate a relevant role of Icl1 in facilitating commensalism of C. albicans in the gastrointestinal tract of mice.

\section{Discussion}

The ability to colonize the mammalian gastrointestinal tract is a key trait in C. albicans, as many of the nosocomial systemic fungemia have an endogenous origin via dissemination from the gastrointestinal pool. Therefore, understanding which factors promote the colonization of this fungus in the gut may have important practical consequences.

The Wor1 regulator has been described as a factor promoting increased fitness in mouse intestine [27] and it triggers in vivo an epigenetic switch that enables colonization. Our in vitro proteomic analyses revealed that overexpression of WOR1 is associated with a change in the pattern of carbon source assimilation, with a reduction in the ability to use certain fermentable and $2 \mathrm{C}$ sources. These changes are in concordance with those already observed in a previous transcriptomic analysis [27], with a downregulation of genes involved in the catabolism of glucose and also with some changes observed in an extensive opaque cell phenotypic profiling study [50]. Our proteomic analysis revealed a significant decrease in proteins involved in carbon metabolism and nutrient acquisition processes. In particular, we found Icl1 (isocitrate lyase), Pck1 (phosphoenolpyruvate kinase), Adh5 (alcohol dehydrogenase), Glx3 (glutathione-independent glyoxalase), or the high affinity transporters for glucose Hgt1 and Hgt19. Pck1 and Glx3 participate in the metabolism of pyruvate, the final product of glycolysis. Pyruvate can enter the mitochondria and produces acetyl-CoA or remains in the cytoplasm to generate lactate or ethanol involving Adh5 activity. The differential metabolic profile observed in the 
WOR $1^{\mathrm{OE}}$ strain suggests a decrease in glycolysis and an increase in gluconeogenesis, in accordance with the transcriptomic data reported by Pande and co-workers [27]. Moreover, the decrease in glycolytic enzymes may explain the hypersensitivity to sodium azide exhibited by WOR1 ${ }^{O E}$ cells [38]. These cells, thus, become more dependent on the ATP generated by the electron transport chain.

Icl1 is a key enzyme in the glyoxylate pathway which enables the use of $2 \mathrm{C}$ sources bypassing the decarboxylation steps of the Krebs cycle enabling gluconeogenesis. It is therefore important for growth in nutrient-limited environments such as those that occur inside phagocytic cells where lipids and amino acids can be used as an alternative to hexose depletion and the glyoxylate cycle, $\beta$-oxidation, and gluconeogenesis metabolic pathways are required to use less favored carbon sources. These pathways have been shown to be important during systemic infection since deletion of genes encoding key enzymes in the pathways, such as FOX2 ( $\beta$-oxidation), ICL1 (glyoxylate cycle), or FBP1 (gluconeogenesis), confer virulence defects to a different extent [42]. Thus, it seems that $C$. albicans acquires and assimilates nonfermentable (non-sugar) compounds not only as an alternative carbon source during infection [41] but also during colonization, as shown by the reduced fitness of icl1 $\Delta / \Delta$ mutants in mouse GI. The glyoxylate cycle takes place in peroxisomes which are involved in fatty acid metabolism [51], and therefore one explanation for this result would invoke fatty acid assimilation. The availability of glucose is scarce in rodent food and would be very limited in distal regions of the GI where the use of alternative carbon sources (such as fatty acids) could be relevant. The concentration of fatty acids changes along the GI tract and it has been shown that a coconut oil diet enriched in medium-chain fatty acids alters the fungal load of $C$. albicans in mouse GI [52]. The ability to use 2C compounds or other carbon sources such as glycerol could be, additionally, important only in specific locations of the gut (e.g., distal part) or after a specific period of adaptation of the fungal cells [53]. Since C. albicans usually depends on the mitochondrial oxidative phosphorylation to obtain energy, metabolic adaptation is crucial for $C$. albicans to survive and colonize the intestine. We found that WOR1 overexpression caused a reduction in the amount of Icl1. However, as deletion of ICL1 impairs the use of nonfermentable carbon sources this result is in apparent contradiction with the proposed role of WOR1 in promoting colonization. This would indicate the existence of ICL1-independent but WOR1-dependent mechanisms for adaptation to the GI tract, that is, downregulation of the glyoxylate cycle would be compensated by other mechanisms that remain to be discovered. Such mechanisms could involve adhesion to the mucosal surfaces, resistance to stressful conditions found in the GI tract (detergents such as bile salts, oxidants, $\mathrm{pH}$, oxygen availability, etc.) or competition with the endogenous microbiota. In any case, caution must be taken while analyzing these data, as our proteomic analysis was carried out under well-defined laboratory conditions (as occurs with related studies on opaque and GUT cells) and the actual conditions in the mammalian gut are clearly different and complex.

The proteomic changes observed were only partially coincident with those observed for previous transcriptional studies on opaque cells [21-23] and GUT cells [27]. A detailed analysis of coincidences and discrepancies is shown in the Supplementary List. It should be noted that, ICL1 is described as an opaque specific gene in two of these publications [21,23] and its expression is augmented in GUT cells versus white a / $\alpha$ cells but not versus opaque cells [27], suggesting it could be related to WOR1. The expression of several white specific genes is decreased in WOR1 ${ }^{O E}$ in our proteomic analysis (ASR1, HSP21, IFE2, HSP12, and GIS2) but there are also some opaque genes with reduced levels such as the mentioned ICL1, PST2 (encoding a flavoredoxin), FDH1 (encoding a formate reductase), and orf19.94 (unknown function). Regarding those proteins with increased abundance in this study in WOR1 ${ }^{O E}$, most of them are identified as opaque specific (e.g., OP4, a usual reporter of the opaque phase) but there are some white specific genes such as orf19.1691 (a putative plasma membrane protein) or TPO4 (a putative spermidine transporter). This analysis reveals an overall reasonable degree of concordance among these studies but also highlights discrepancies as expected from different morphogenetic programs. In addition, both the methodology (mRNA, protein) and 
the experimental conditions used for the study (temperature, nutrient, and phase of growth) can clearly influence the outcome and interpretation of the results.

Another important result from this work is that the glyoxylate cycle participates in the generation of phloxine B positive cells, which is a characteristic of WOR1 overexpression. The ability to retain this fluorochrome is also a landmark of opaque cells; however, opaque cells differ from $W O R 1^{O E}$ cells by their elongated morphology, heat sensitivity, the existence of protuberances in the surface, and mating competent status; they are able to form mating projections and are generated via a spontaneous epigenetic switch through mating type repression release and not via ectopic overexpression of WOR1. They have a characteristic transcriptional program [21,22] which is only partially overlapping with those of GUT cells [27]. As deletion of ICL1 in hemizygous $\alpha$-mating-type cells reduces the frequency of opaque cell formation and overexpression of WOR1 partially restores the generation of phloxine B positive cells, these results clearly point to a positive role of Icl1 in the wo transition. Nevertheless, when the ICL1 gene was overexpressed in a wor1 mutant, cells did not become phloxine B positive (data not shown), indicating the dominant effect of WOR1 over ICL1 in wo switching. As the glyoxylate cycle takes place in peroxisomes, organelles involved in lipid beta-oxidation among other functions [54], a proposed explanation is that C. albicans $i c l 1 \Delta / \Delta$ mutants are somehow altered in lipid homeostasis which would render cells less permeable to phloxine B. In any case, as WOR $1^{O E}$ does not restore colonization levels of $i c l 1 \Delta / \Delta$ mutants, this indicates that phoxine B positiveness cannot be taken as a trait of the adapted GI form in C. albicans per se.

In conclusion, we show that the glyoxylate shunt pathway is involved in colonization of mouse GI by mechanisms that are independent of the transcriptional wo regulator Wor1 and the generation of phloxine B positive cells. Understanding how these changes promote adaptation to the gastrointestinal niche open the possibility to control C. albicans colonization for therapeutic purposes.

Supplementary Materials: The following are available online at https:/ /www.mdpi.com/article/10 .3390/jof7070502/s1, Supplementary List.

Author Contributions: Conceptualization, S.H.V., R.A.M., E.R., D.P. and J.P.; methodology, S.H.V. and D.P.; formal analysis, S.H.V., E.R., D.P., R.A.M. and J.P.; investigation, S.H.V. and D.P.; data curation, S.H.V. and D.P.; writing—original draft preparation, E.R. and J.P.; writing—review and editing, J.P., E.R. and R.A.M.; project administration, J.P.; funding acquisition, J.P. and R.A.M. All authors have read and agreed to the published version of the manuscript.

Funding: This research was funded by grants PGC2018-095047-B-I00 from MINECO and InGEMICS (B2017/BMD-3691) from CAM.

Institutional Review Board Statement: The study was conducted according to the guidelines of the Declaration of Helsinki, and approved by the Animal Experimentation Committee of the University Complutense of Madrid (CEA 33-2015) and Comunidad de Madrid according to Artículo 34 del RD 53/2013 (PROEX 226/15).

Informed Consent Statement: Not applicable.

Data Availability Statement: Not applicable.

Acknowledgments: We thank M. Lorenz for sharing icl1 $\Delta / \Delta$ strains.

Conflicts of Interest: The authors declare no conflict of interest.

\section{References}

1. Gudlaugsson, O.; Gillespie, S.; Lee, K.; Berg, J.V.; Hu, J.; Messer, S.; Herwaldt, L.; Pfaller, M.; Diekema, D. Attributable Mortality of Nosocomial Candidemia, Revisited. Clin. Infect. Dis. 2003, 37, 1172-1177. [CrossRef]

2. Pappas, P.G.; Lionakis, M.S.; Arendrup, M.C.; Ostrosky-Zeichner, L.; Kullberg, B.J. Invasive candidiasis. Nat. Rev. Dis. Primers 2018, 4, 18026. [CrossRef]

3. Brown, G.D.; Denning, D.W.; Gow, N.A.R.; Levitz, S.M.; Netea, M.G.; White, T.C. Hidden killers: Human fungal infections. Sci. Transl. Med. 2012, 4, 165rv113. [CrossRef]

4. Mayer, F.L.; Wilson, D.; Hube, B. Candida albicans pathogenicity mechanisms. Virulence 2013, 4, 119-128. [CrossRef] 
5. Koh, A.Y. Murine models of Candida gastrointestinal colonization and dissemination. Eukaryot. Cell 2013, 12, 1416-1422. [CrossRef]

6. Magill, S.S.; Swoboda, S.M.; Johnson, E.A.; Merz, W.G.; Pelz, R.K.; Lipsett, P.A.; Hendrix, C.W. The association between anatomic site of Candida colonization, invasive candidiasis, and mortality in critically ill surgical patients. Diagn. Microbiol. Infect. Dis. 2006, 55, 293-301. [CrossRef]

7. Miranda, L.N.; van der Heijden, I.M.; Costa, S.F.; Sousa, A.P.; Sienra, R.A.; Gobara, S.; Santos, C.R.; Lobo, R.D.; Pessoa, V.P., Jr.; Levin, A.S. Candida colonisation as a source for candidaemia. J. Hosp. Infect. 2009, 72, 9-16. [CrossRef]

8. Voss, A.; Hollis, R.J.; Pfaller, M.A.; Wenzel, R.P.; Doebbeling, B.N. Investigation of the sequence of colonization and candidemia in nonneutropenic patients. J. Clin. Microbiol. 1994, 32, 975-980. [CrossRef]

9. Marco, F.; Lockhart, S.R.; Pfaller, M.A.; Pujol, C.; Rangel-Frausto, M.S.; Wiblin, T.; Blumberg, H.M.; Edwards, J.E.; Jarvis, W.; Saiman, L.; et al. Elucidating the origins of nosocomial infections with Candida albicans by DNA fingerprinting with the complex probe Ca3. J. Clin. Microbiol. 1999, 37, 2817-2828. [CrossRef]

10. Prieto, D.; Correia, I.; Pla, J.; Román, E. Adaptation of Candida albicans to commensalism in the gut. Future Microbiol. 2016, 11, 567-583. [CrossRef]

11. Witchley, J.N.; Penumetcha, P.; Abon, N.V.; Woolford, C.A.; Mitchell, A.P.; Noble, S.M. Candida albicans Morphogenesis Programs Control the Balance between Gut Commensalism and Invasive Infection. Cell Host Microbe 2019, 25, 432-443.e6. [CrossRef] [PubMed]

12. Neville, B.A.; d'Enfert, C.; Bougnoux, M.E. Candida albicans commensalism in the gastrointestinal tract. FEMS Yeast Res. 2015, 15, fov081. [CrossRef]

13. Noble, S.M. Candida albicans specializations for iron homeostasis: From commensalism to virulence. Curr. Opin. Microbiol. 2013, 16, 708-715. [CrossRef]

14. Perez, J.C.; Kumamoto, C.A.; Johnson, A.D. Candida albicans commensalism and pathogenicity are intertwined traits directed by a tightly knit transcriptional regulatory circuit. PLoS Biol. 2013, 11, e1001510. [CrossRef]

15. Pierce, J.V.; Kumamoto, C.A. Variation in Candida albicans EFG1 expression enables host-dependent changes in colonizing fungal populations. MBio 2012, 3, e00117-12. [CrossRef] [PubMed]

16. Vautier, S.; Drummond, R.A.; Chen, K.; Murray, G.I.; Kadosh, D.; Brown, A.J.; Gow, N.A.; MacCallum, D.M.; Kolls, J.K.; Brown, G.D. Candida albicans colonization and dissemination from the murine gastrointestinal tract: The influence of morphology and Th17 immunity. Cell. Microbiol. 2015, 17, 445-450. [CrossRef]

17. Prieto, A.D.; Román, E.; Correia, I.; Pla, J. The HOG pathway is critical for the colonization of the mouse gastrointestinal tract by Candida albicans. PLoS ONE 2014, 9, e87128.

18. Ramírez-Zavala, B.; Mottola, A.; Haubenreißer, J.; Schneider, S.; Allert, S.; Brunke, S.; Ohlsen, K.; Hube, B.; Morschhäuser, J. The Snf1-activating kinase Sak1 is a key regulator of metabolic adaptation and in vivo fitness of Candida albicans. Mol. Microbiol. 2017, 104, 989-1007. [CrossRef]

19. Román, E.; Huertas, B.; Prieto, D.; Diez-Orejas, R.; Pla, J. TUP1-mediated filamentation in Candida albicans leads to inability to colonize the mouse gut. Future Microbiol. 2018, 13, 857-867. [CrossRef]

20. Soll, D.R. The role of phenotypic switching in the basic biology and pathogenesis of Candida albicans. J. Oral Microbiol. 2014, 6 . [CrossRef]

21. Tuch, B.B.; Mitrovich, Q.M.; Homann, O.R.; Hernday, A.D.; Monighetti, C.K.; De La Vega, F.M.; Johnson, A.D. The transcriptomes of two heritable cell types illuminate the circuit governing their differentiation. PLoS Genet. 2010, 6, e1001070. [CrossRef]

22. Lan, C.Y.; Newport, G.; Murillo, L.A.; Jones, T.; Scherer, S.; Davis, R.W.; Agabian, N. Metabolic specialization associated with phenotypic switching in Candida albicans. Proc. Natl. Acad. Sci. USA 2002, 99, 14907-14912. [CrossRef]

23. Tsong, A.E.; Miller, M.G.; Raisner, R.M.; Johnson, A.D. Evolution of a combinatorial transcriptional circuit: A case study in yeasts. Cell 2003, 115, 389-399. [CrossRef]

24. Kvaal, C.; Lachke, S.A.; Srikantha, T.; Daniels, K.; McCoy, J.; Soll, D.R. Misexpression of the opaque-phase-specific gene PEP1 (SAP1) in the white phase of Candida albicans confers increased virulence in a mouse model of cutaneous infection. Infect. Immun. 1999, 67, 6652-6662. [CrossRef]

25. Kvaal, C.A.; Srikantha, T.; Soll, D.R. Misexpression of the white-phase-specific gene WH11 in the opaque phase of Candida albicans affects switching and virulence. Infect. Immun. 1997, 65, 4468-4475. [CrossRef]

26. Srikantha, T.; Borneman, A.R.; Daniels, K.J.; Pujol, C.; Wu, W.; Seringhaus, M.R.; Gerstein, M.; Yi, S.; Snyder, M.; Soll, D.R. TOS9 regulates white-opaque switching in Candida albicans. Eukaryot. Cell 2006, 5, 1674-1687. [CrossRef] [PubMed]

27. Pande, K.; Chen, C.; Noble, S.M. Passage through the mammalian gut triggers a phenotypic switch that promotes Candida albicans commensalism. Nat. Genet. 2013, 45, 1088-1091. [CrossRef]

28. Huang, G.; Wang, H.; Chou, S.; Nie, X.; Chen, J.; Liu, H. Bistable expression of WOR1, a master regulator of white-opaque switching in Candida albicans. Proc. Natl. Acad. Sci. USA 2006, 103, 12813-12818. [CrossRef]

29. Zordan, R.E.; Galgoczy, D.J.; Johnson, A.D. Epigenetic properties of white-opaque switching in Candida albicans are based on a self-sustaining transcriptional feedback loop. Proc. Natl. Acad. Sci. USA 2006, 103, 12807-12812. [CrossRef]

30. Zordan, R.E.; Miller, M.G.; Galgoczy, D.J.; Tuch, B.B.; Johnson, A.D. Interlocking transcriptional feedback loops control whiteopaque switching in Candida albicans. PLoS Biol. 2007, 5, e256. [CrossRef] [PubMed]

31. Hernday, A.D.; Lohse, M.B.; Fordyce, P.M.; Nobile, C.J.; DeRisi, J.L.; Johnson, A.D. Structure of the transcriptional network controlling white-opaque switching in Candida albicans. Mol. Microbiol. 2013, 90, 22-35. [CrossRef] [PubMed] 
32. Lohse, M.B.; Ene, I.V.; Craik, V.B.; Hernday, A.D.; Mancera, E.; Morschhauser, J.; Bennett, R.J.; Johnson, A.D. Systematic Genetic Screen for Transcriptional Regulators of the Candida albicans White-Opaque Switch. Genetics 2016, 203, 1679-1692. [CrossRef]

33. Stevenson, J.S.; Liu, H. Regulation of white and opaque cell-type formation in Candida albicans by Rtt109 and Hst3. Mol. Microbiol. 2011, 81, 1078-1091. [CrossRef]

34. Srikantha, T.; Tsai, L.; Daniels, K.; Klar, A.J.; Soll, D.R. The histone deacetylase genes HDA1 and RPD3 play distinct roles in regulation of high-frequency phenotypic switching in Candida albicans. J. Bacteriol. 2001, 183, 4614-4625. [CrossRef] [PubMed]

35. Hnisz, D.; Schwarzmuller, T.; Kuchler, K. Transcriptional loops meet chromatin: A dual-layer network controls white-opaque switching in Candida albicans. Mol. Microbiol. 2009, 74, 1-15. [CrossRef] [PubMed]

36. Stoldt, V.R.; Sonneborn, A.; Leuker, C.E.; Ernst, J.F. Efg1p, an essential regulator of morphogenesis of the human pathogen Candida albicans, is a member of a conserved class of bHLH proteins regulating morphogenetic processes in fungi. EMBO J. 1997, 16, 1982-1991. [CrossRef]

37. Sonneborn, A.; Tebarth, B.; Ernst, J.F. Control of white-opaque phenotypic switching in Candida albicans by the Efg1p morphogenetic regulator. Infect. Immun. 1999, 67, 4655-4660. [CrossRef]

38. Prieto, D.; Román, E.; Alonso-Monge, R.; Pla, J. Overexpression of the Transcriptional Regulator WOR1 Increases Susceptibility to Bile Salts and Adhesion to the Mouse Gut Mucosa in Candida albicans. Front. Cell. Infect. Microbiol. 2017, 7, 389. [CrossRef]

39. Fonzi, W.A.; Irwin, M.Y. Isogenic strain construction and gene mapping in Candida albicans. Genetics 1993, 134, 717-728. [CrossRef]

40. Román, E.; Correia, I.; Salazin, A.; Fradin, C.; Jouault, T.; Poulain, D.; Liu, F.T.; Pla, J. The Cek1-mediated MAP kinase pathway regulates exposure of $\alpha-(1,2)$ and $\beta-(1,2)$-mannosides in the cell wall of Candida albicans modulating immune recognition. Virulence 2016, 7, 558-577. [CrossRef]

41. Lorenz, M.C.; Fink, G.R. The glyoxylate cycle is required for fungal virulence. Nature 2001, 412, 83-86. [CrossRef]

42. Ramirez, M.A.; Lorenz, M.C. Mutations in alternative carbon utilization pathways in Candida albicans attenuate virulence and confer pleiotropic phenotypes. Eukaryot. Cell 2007, 6, 280-290. [CrossRef]

43. Shapiro, R.S.; Chavez, A.; Porter, C.B.M.; Hamblin, M.; Kaas, C.S.; DiCarlo, J.E.; Zeng, G.; Xu, X.; Revtovich, A.V.; Kirienko, N.V.; et al. A CRISPR-Cas9-based gene drive platform for genetic interaction analysis in Candida albicans. Nature Microbiol. 2018, 3 , 73-82. [CrossRef] [PubMed]

44. Min, K.; Ichikawa, Y.; Woolford, C.A.; Mitchell, A.P. Candida albicans Gene Deletion with a Transient CRISPR-Cas9 System. mSphere 2016, 1, e00130-16. [CrossRef] [PubMed]

45. Román, E.; Coman, I.; Prieto, D.; Alonso-Monge, R.; Pla, J. Implementation of a CRISPR-Based System for Gene Regulation in Candida albicans. mSphere 2019, 4, e0001-19. [CrossRef]

46. Vyas, V.K.; Barrasa, M.I.; Fink, G.R. A CRISPR system permits genetic engineering of essential genes and gene families. Sci. Adv. 2015, 1, e1500248. [CrossRef]

47. Martin, H.; Rodriguez-Pachon, J.M.; Ruiz, C.; Nombela, C.; Molina, M. Regulatory mechanisms for modulation of signaling through the cell integrity Slt2-mediated pathway in Saccharomyces cerevisiae. J. Biol. Chem. 2000, 275, 1511-1519. [CrossRef] [PubMed]

48. Rico-San Román, L.; Horcajo, P.; Regidor-Cerrillo, J.; Fernández-Escobar, M.; Collantes-Fernández, E.; Gutiérrez-Blázquez, D.; Hernáez-Sánchez, M.L.; Saeij, J.P.J.; Ortega-Mora, L.M. Comparative tachyzoite proteome analyses among six Neospora caninum isolates with different virulence. Int. J. Parasitol. 2020, 50, 377-388. [CrossRef] [PubMed]

49. Park, Y.N.; Morschhauser, J. Tetracycline-inducible gene expression and gene deletion in Candida albicans. Eukaryot. Cell 2005, 4, 1328-1342. [CrossRef] [PubMed]

50. Ene, I.V.; Lohse, M.B.; Vladu, A.V.; Morschhauser, J.; Johnson, A.D.; Bennett, R.J. Phenotypic Profiling Reveals that Candida albicans Opaque Cells Represent a Metabolically Specialized Cell State Compared to Default White Cells. MBio 2016, 7. [CrossRef]

51. Piekarska, K.; Hardy, G.; Mol, E.; van den Burg, J.; Strijbis, K.; van Roermund, C.; van den Berg, M.; Distel, B. The activity of the glyoxylate cycle in peroxisomes of Candida albicans depends on a functional beta-oxidation pathway: Evidence for reduced metabolite transport across the peroxisomal membrane. Microbiology 2008, 154, 3061-3072. [CrossRef] [PubMed]

52. Gunsalus, K.T.; Tornberg-Belanger, S.N.; Matthan, N.R.; Lichtenstein, A.H.; Kumamoto, C.A. Manipulation of Host Diet To Reduce Gastrointestinal Colonization by the Opportunistic Pathogen Candida albicans. mSphere 2016, 1, e00020-15. [CrossRef] [PubMed]

53. Prieto, D.; Pla, J. Distinct stages during colonization of the mouse gastrointestinal tract by Candida albicans. Front. Microbiol. 2015, 6, 792. [CrossRef] [PubMed]

54. Aksit, A.; van der Klei, I.J. Yeast peroxisomes: How are they formed and how do they grow? Int. J. Biochem. Cell Biol. 2018, 105, 24-34. [CrossRef] [PubMed] 